\title{
Early development of the cephalic skeleton of Barbus barbus (Teleostei, Cyprinidae)
}

\author{
P. Vandewalle*, B. Focant $\dagger$, F. Huriaux $†$ and M. Chardon* \\ *Université de Liège, Laboratoire de Morphologie fonctionnelle, 22, quai Van Beneden, \\ $B-4020$ Liège and $\dagger$ Université de Liège, Laboratoire de Biologie cellulaire et tissulaire, \\ 20, rue de Pitteurs, B-4020 Liège, Belgium
}

(Received 9 September 1991, Accepted 15 November 1991)

\begin{abstract}
The inception, and development of the cephalic skeleton of Barbus barbus from hatching to 24 days passes through periods of fast and slow growth; these rates are not the same in different parts of the skull. Trabeculae, parachordal plates, Meckelian cartilages and hyposymplectics are present at hatching. Then the cartilaginous floor of the neurocranium develops, the pars quadrata, the hyoid bars and branchial arches elements appear shortly before the first movable dermal bones, the den taries, maxillae and opercles. The first bone of the braincase to appear is the parasphenoid; other bones develop subsequently and at the same time: the angular, quadrate, interopercle and fifth ceratobranchial. Later the splanchnocranium continues to develop at a relatively fast rate while the neurocranium shows little growth. The braincase does not begin to close before the 24th day, nor do the first bones of the skull roof appear, while the bucco-pharyngeal apparatus is complete, having the adult shape. The early constitution of the latter structures seems to be linked with the mechanical demands of biological functions such as breathing and feeding.
\end{abstract}

Key words: Cyprinidae; Barbus barbus; skull development.

\section{INTRODUCTION}

Embryonic and larval development of the teleostean skull have been investigated for many years (Parker, 1873; Stöhr, 1882; Tischomiroff, 1885; Winslow, 1898; Swinnerton, 1902; Gaupp, 1903). Many authors observed only the external aspect of the head (latterly: Able et al., 1986; Munehara \& Mishima, 1986; Nishikawa, 1987; Fukuhara, 1988; Krupka, 1988) or of a part of the skull: the osteocranium (Morris \& Gaudin, 1982; Jollie, 1984; Pottoff et al., 1988) or the chondrocranium (Wells, 1923; Bhargava, 1958; Bertmar, 1959). Few described the entire skull (Kindred, 1919; Bamford, 1948; Elman \& Balon, 1980). A number of specialized papers deal with certain elements of the skull (Haines, 1937; Devillers, 1944; Lekander, 1949; Corsin, 1961; Kapoor, 1970; Francillon, 1974; Arratia \& Schultze, 1990), sometimes in a functional perspective (Verraes, 1974, 1977). Some authors described a limited number of developmental stages (Srinivasachar, 1958; Howes \& Sanford, 1987; Surlemont \& Vandewalle, 1991). Comprehensive syntheses of the teleostean skull development are due to De Beer (1937) and Daget (1964).

Few studies provide a discrete comparative timing of the events occurring during the development of the skull of a teleost. Our aim is to describe the chronological sequence of morphological events associated with the appearance of the cephalic movements and with their changes during the larval life of Barbus barbus (Linné, 1758). Such results are necessary to understand the evolution of functions such as respiration and feeding which are essential for fry survival. 


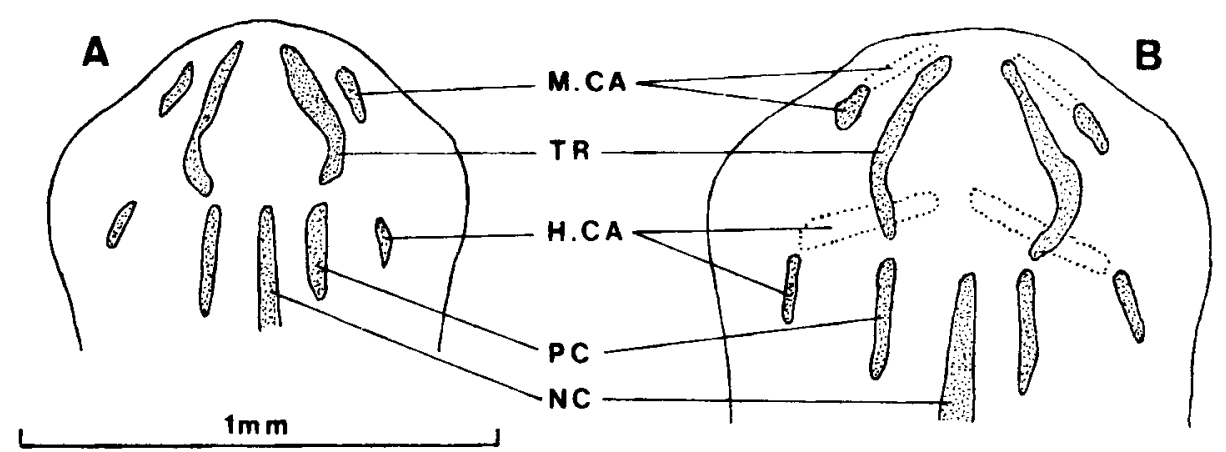

FIG. 1. Barbus barbus, dorsal view of the cartilaginous skull of 4-day-old fry (at hatching) (A) and 5-day-old fry (B). Dotted lines represent unclear limits. Abbreviations: H.CA, hyoid cartilage; M.CA, Meckel's cartilage; NC, notochord; PC, parachordal plate; TR, trabecular bar.

The present paper deals with the morphological development of the skull from hatching (4 days after fertilization) to 24 days, which means in our culture condition the end of larval life as defined by Krupka (1988), that is to say when the mouth definitively opens ventrally as it does in adults (Vandewalle, 1977). The nomenclature of the developing cranial elements follows De Beer (1937) and Daget (1964).

\section{MATERIAL, TECHNIQUES AND METHODS}

Fry were raised in the experimental pisciculture of the CERER (Tihange, Belgium) at $24^{\circ} \mathrm{C}$. Groups of 20 fry were sampled at 4 days (at hatching), 5, 6, 7, 8, 10, 12, 14, 16, 20 and 24 days after fertilization and fixed in $\mathrm{CaCO}_{3}$ buffered $10 \%$ formalin solution. Fry were cleared in trypsin. Some of them were stained with alcian blue to reveal the cartilages and others with alizarine, which stains calcified bones, according to Taylor and Van Dyke's method (1985). It has not been possible to stain them simultaneously with alizarine and alcian.

Figures 1 to 10 depict the medium level of skeletal development of every sample of fry. Cartilage and bone were most often observed on different specimens. To avoid any modification needed to match drawings of these different specimens, it was decided to present the cartilaginous skeleton and the bony one as separate diagrams including the case when an enchondral ossification is developing from a cartilaginous anlage (as in Figs 5 to 10).

Although the presentation of the results begins with the fry at hatching, homologies were established and structures were recognized by comparing adult structures to those of earlier stages.

\section{RESULTS}

\section{4-DAY-OLD FRY (7.6 MM, HATCHING) [FIG. 1(A)]}

At hatching, some cartilaginous structures are already conspicuous. Anteriortrabeculae and discrete parachordals are the first parts of the base of the neurocranium, which appears before the roof(Daget, 1964). Meckel's cartilage and hyoid cartilage, determined as the hyosymplectic by comparison with the 6-day-old fry, are also present. 

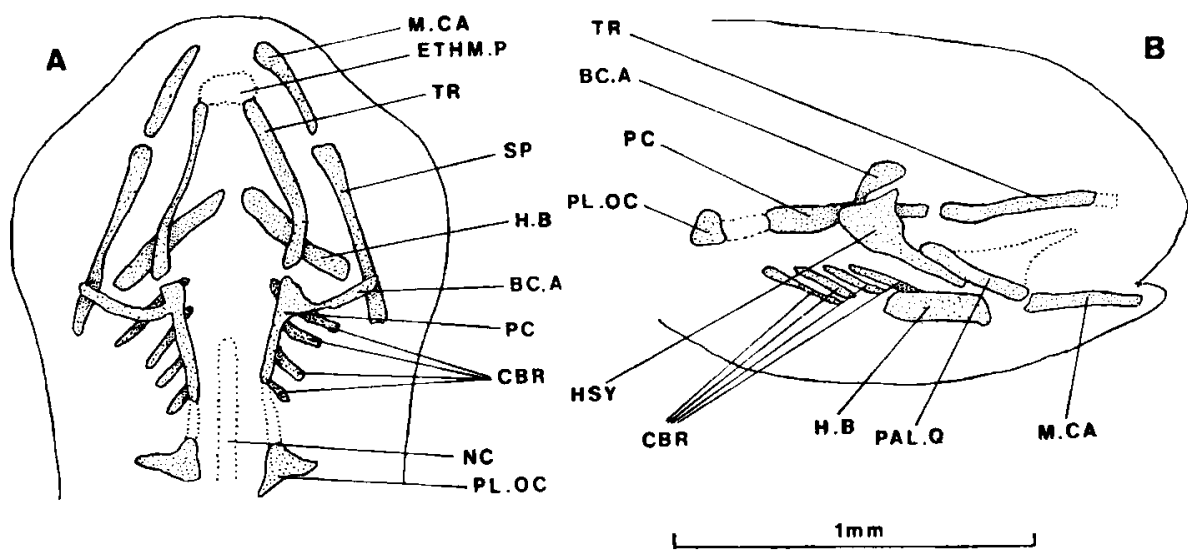

FIG. 2. Barbus barbus, dorsal (A) and lateral (B) views of the cartilaginous skull of 6-day-old fry. Dotted lines represent unclear limits. Abbreviations: BC.A, commissura basicapsularis anterior; CBR, ceratobranchial; ETHM.P, ethmoid plate; H.B, hyoid bar; HSY, hyosymplectic; M.CA, Meckel's cartilage; NC, notochord; PAL.Q, palato-quadrate; PC, parachordal plate; PL.OC, pila occipitalis; SP, suspensorium; TR, trabecular bar.

\section{5-DAY-OLD FRY (8.9 MM) [FIG. 1(B)]}

Trabecular bars are somewhat more developed, but remain separated from the parachordal plates. Meckel's cartilages extend forward and a second pair of hyoid primordia appears: the hyoid bars.

\section{6-DAY-OLD FRY (9 MM) (FIG. 2)}

Anteriorly, the trabecular bars fuse to initiate the ethmoideal plate, but posteriorly they are still distinct from the parachordal plates. The latter develop laterally and upward as anterior basicapsular commissurae. Pilae occipitales are present.

The splanchnocranium has progressed. In addition to Meckel's cartilage, there is a suspensorium consisting of a larger hyosymplectic and a palato-quadrate provided with the primordium of a processus pterygoideus. The hyoid bar is strengthened and there are four ceratobranchials.

\section{7-DAY-OLD FRY (9.9 MM) (FIG. 3)}

The ethmoideal plate is present but not clearly limited anteriorly.

Trabecular bars are fused with the parachordal plates, which are contiguous with the pilae occipitales. The anterior basicapsular commissurae are anteriorly prolonged by the short taeniae marginales and posteriorly they extend to the pilae occipitales.

To the splanchnocranium are added a processus pterygoideus, an interhyal from which cartilaginous buds extend in the direction of the hyosymplectic and hyoid bar, fifth ceratobranchials and cartilaginous primordia of basibranchials and hypobranchials.

\section{8-DAY-OLD FRY (10.5 MM) (FIG. 4)}

The ethmoid plate is enlarged and the hypophyseal fenestra is reduced, but not yet closed posteriorly because the left and right parachordal plates do not fuse in the midline. The floor and the lateral walls of the otic capsules are formed. The processus pterygoideus is complete. The interhyal is fused with the hyoid bar and 


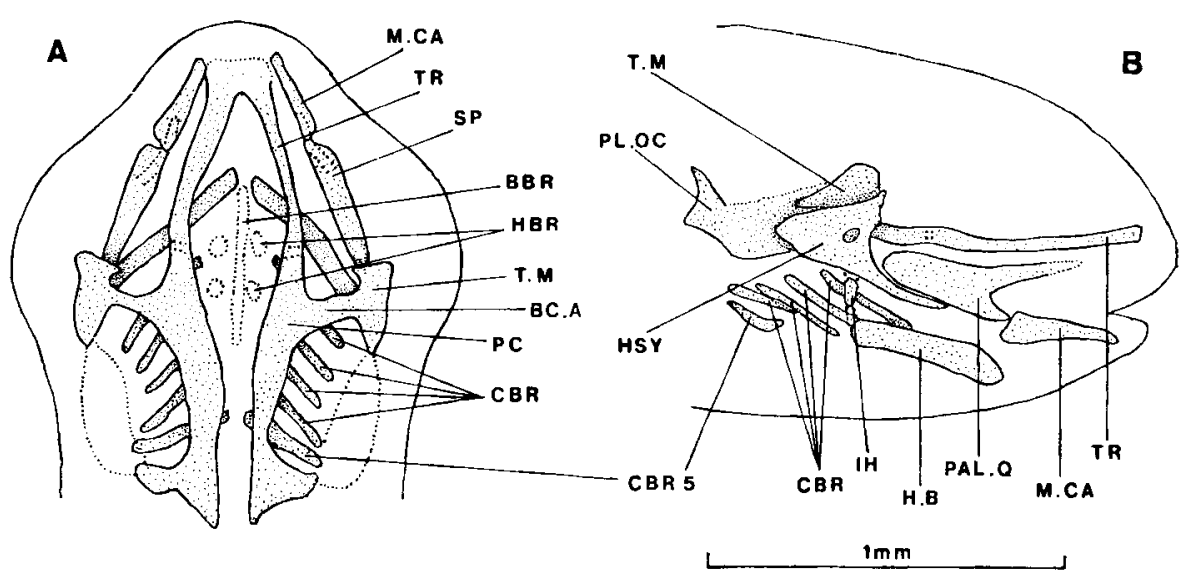

Fig. 3. Barbus barbus, dorsal (A) and lateral (B) views of the cartilaginous skull of 7-day-old fry. Dotted lines represent unclear limits. Abbreviations: BBR, basibranchial; BC.A, commissura basicapsularis anterior; CBR, ceratobranchial; CBR 5, 5th ceratobranchial; H.B, hyoid bar; HBR, hypobranchial; HSY, hyosymplectic; IH, interhyal; M.CA, Meckel's cartilage; PAL.Q, palato-quadrate; PC, parachordal plate; PL.OC, pila occipitalis; SP, suspensorium; T.M, taenia marginalis; TR, trabecular bar.

reaches the hyosymplectic. The basihyal is present as are two pairs of well-developed hypobranchials, and one more pair developing.

The first bony primordia appear at 8 days. Except for the perichordal ossifications, all are dermal ossifications: the well-developed opercles and dentaries, the maxillaries, the angulars, the retroarticulars and one pair of branchiostegal rays.

\section{0-DAY-OLD FRY (11.1 MM) (FIG. 5)}

The stage corresponds to Krupka's (1988) last embryonic stage, the vitelline vesicle of which is beginning to disappear. Perichordal ossification is present.

The ethmoid plate is the anterior limit of the chondral neurocranium; it bears two lateral processes. The hypophyseal fenestra is not yet completely closed posteriorly either by cartilage or by the just formed parasphenoid bone which makes its aperture narrower. The taeniae marginales curve inwards. The lateral walls of the otic capsules develop upward. The foramen of the trigemino-facialis chamber opens between the anterior basicapsular commissura and the lateral wall of the neurocranium. The first neurocranial ossification is the parasphenoid which partly closes the hypophyseal fenestra.

Cartilage and bone progress in the splanchnocranium. Two more pairs of hypobranchials are present, the posterior (fourth) one being in the process of chondrification, as is the hind part of the basibranchial which reach the fifth ceratobranchials, the latter partly ossified. A quadratal ossification appears in the palatoquadrate. Many dermal plates are now present or enlarged: operculum, interoperculum, angular, dentary and maxillary.

\section{2-DAY-OLD FRY (12.4 MM) (FIG. 6)}

The epiphyseal bridge is completed. The ethmoid plate bears two more processes dorsally, the laminae orbito-nasales. The upper parts of the walls of the otic capsules curve inward. The parachordal plates are not yet fused on the midline. The processus pterygoideus of the palato-quadrate is elongated forward to the level 

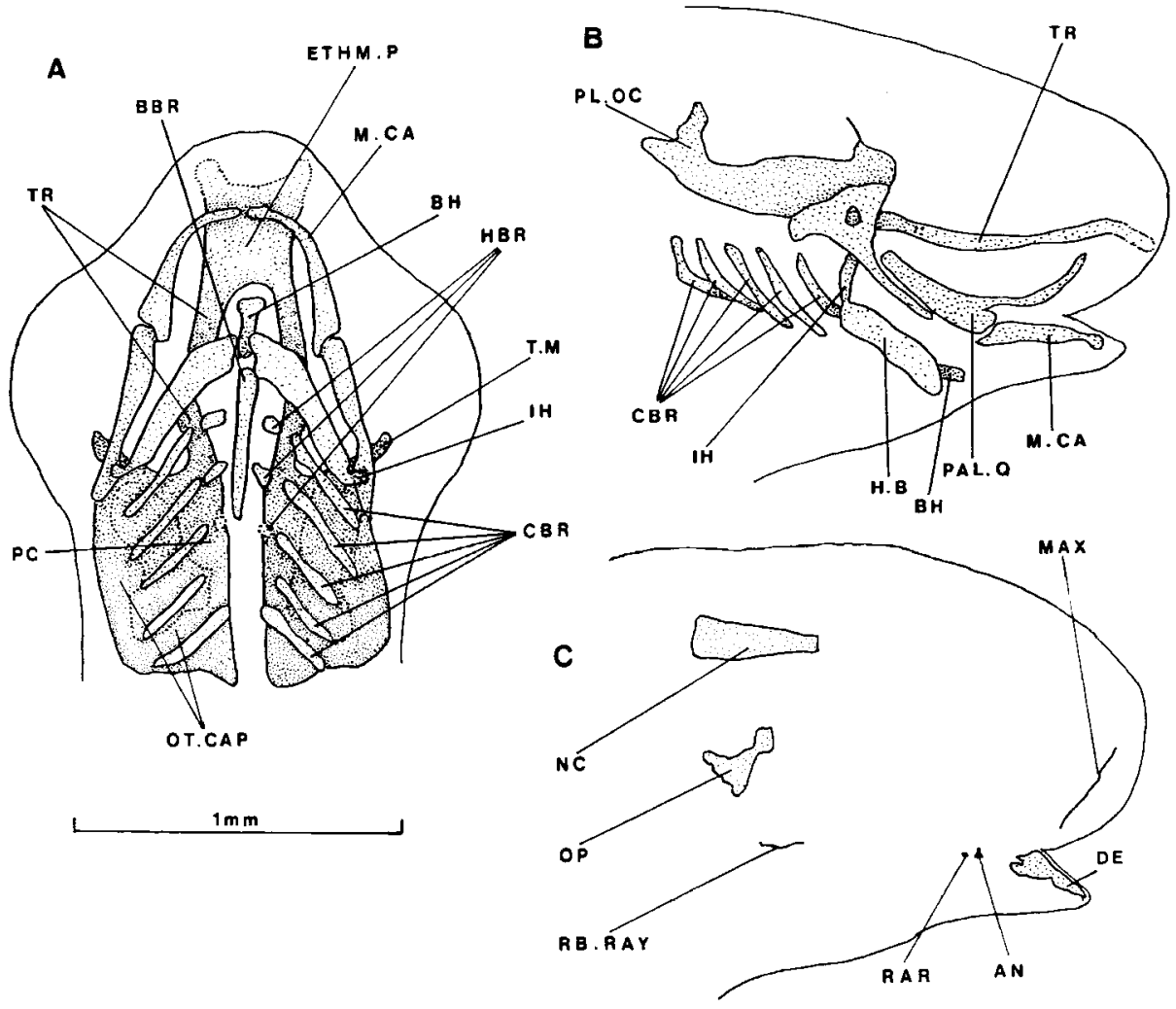

FIG. 4. Barbus barbus, skull of 8-day-old fry. Ventral (A) and lateral (B) views of the cartilages and lateral view of the bony elements (C). Dotted lines represent unclear limits. Abbreviations: AN, angular; BBR, basibranchial; BH, basihyal; BR.RAY, branchiostegal ray; CBR, ceratobranchial; DE, dentary; ETHM.P, ethmoid plate; H.B, hyoid bar; HBR, hypobranchial; IH, interhyal; MAX, maxilla; M.CA, Meckel's cartilage; NC, notochord; OP, opercle; OT.CAP, otic capsule; PAL.Q, palatoquadrate; PC, parachordal plate; RAR, retroarticular; T.M, taenia marginalis; TR, trabecular bar.

of the anterior end of the ethmoid plate. Two lateral exoccipital ossifications develop in the parachordals next to the notochord. The parasphenoid is enlarged.

The branchial arches are further complete with two basibranchials, four pairs of hypobranchials and epibranchials, and one pair of pharyngobranchials between the second and third epibranchials. The fifth ossified ceratobranchials bear two teeth. The interhyals are continuous with the hyosymplectics and the hyoid bars. One hypohyal and one ceratohyal ossification centre develop in the hyoid bar.

A premaxilla is present. The bony lower jaw foreshadows its shape in the adult (Vandewalle, 1977) with an ascending process of the dentary and an angular extending anteriorly on the inner face of the dentary like in other cyprinids (Lekander, 1949).

\section{4-DAY-OLD FRY (13.7 MM) (FIG. 7)}

The yolk sac is resorbed.

The taenia marginalis extends in the direction of the lamina orbito-nasalis. The upper part of the otic capsules continues to extend to the midline but does not fuse medially. 

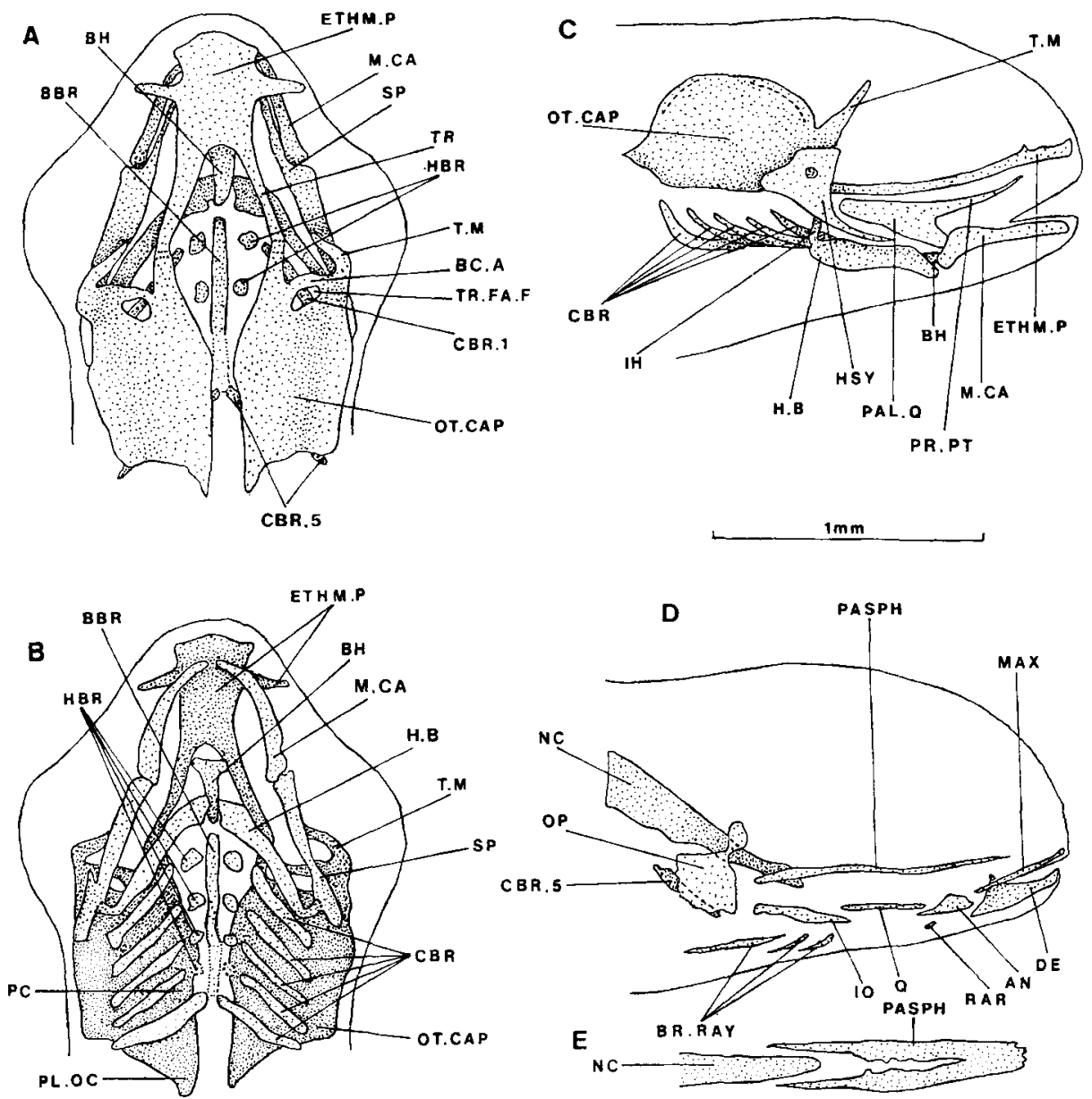

FIG. 5. Barbus barbus, skull of 10-day-old fry. Dorsal (A), ventral (B) and lateral (C) views of the cartilages, lateral view of the bony elements (D) and dorsal view of the parasphenoid on notochord (E). Dotted lines represent unclear limits. Dashes indicate hidden structures. Abbreviations: AN, angular; BBR, basibranchial; BC.A, commissura basicapsularis anterior; BH, basihyal; BR.RAY, branchiostegal ray; CBR, ceratobranchial; CBR 1, ceratobranchial of the first arch; CBR 5, ceratobranchial of the fifth arch; DE, dentary; ETHM.P, ethmoid plate; H.B, hyoid bar; HBR, hypobranchial; HSY, hyosymplectic; IH, interhyal; IO, interopercle; MAX, maxilla; M.CA, Meckel's cartilage; NC, notochord; OP, opercle; OT.CAP, otic capsule; PAL.Q, palato-quadrate; PASPH, parasphenoid; PC, parachordal plate; PL.OC, pila occipitalis; PR.PT, processus pterygoideus; Q, quadrate; RAR, retroarticular; SP, suspensorium; T.M, taenia marginalis; TR.FA.F, foramen of trigemino-facialis chamber.

The still enlarged parasphenoid develops a pair of lateral postorbital processes as in many adult teleosts (see, for example, Taverne, 1974; Winterbottom, 1980; Benmouna et al., 1984) at a level where the trabecular bars seem to be pinched. It extends back to the tip of the notochord so that it encircles a reduced hypophyseal fenestra.

The exoccipitals are enlarged and the early primordia of the cyprinid posterior process of the basiocciptal (Vetter, 1858; Ramaswami, 1955a, b; Ballintijn, 1969; Vandewalle, 1975, 1977) are present. 

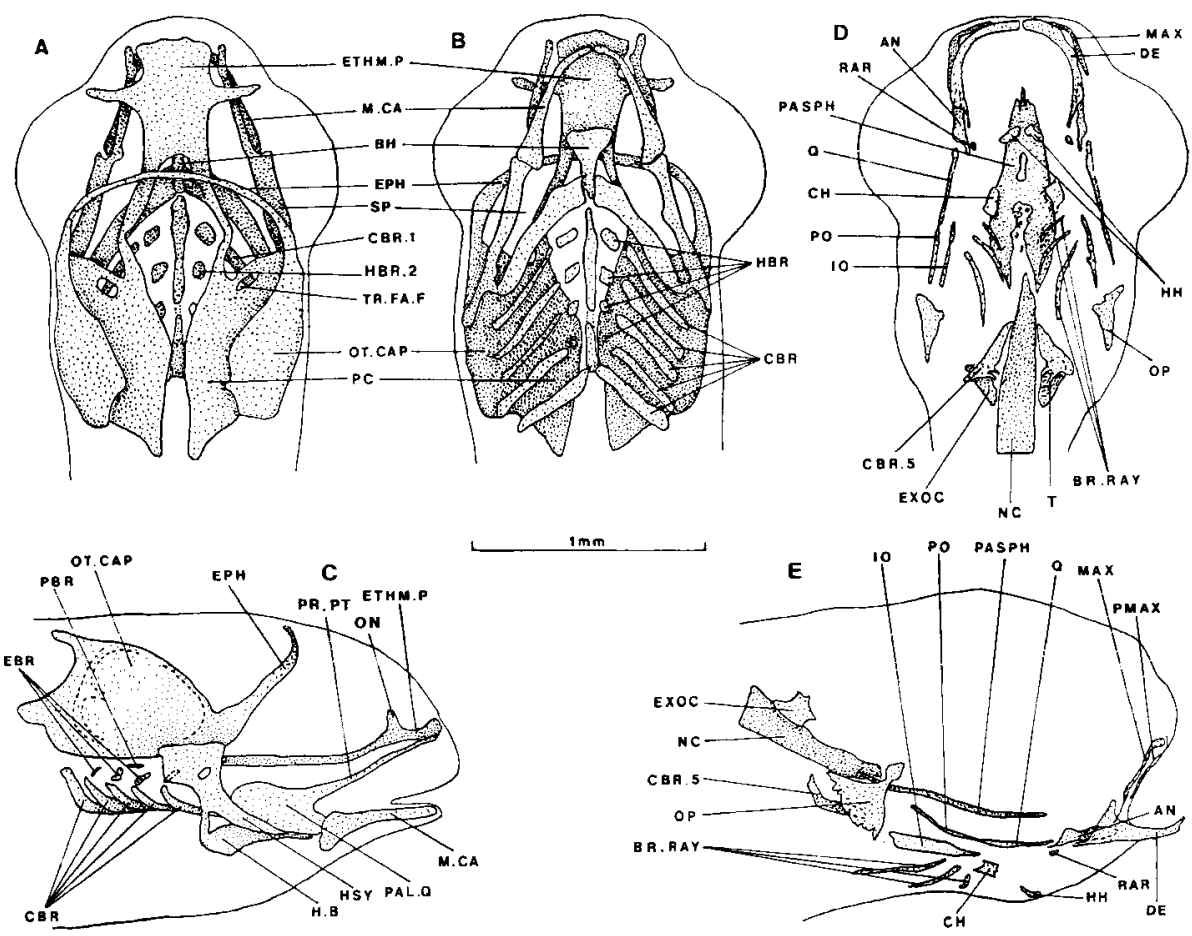

FiG. 6. Barbus barbus, skull of 12-day-old fry. Dorsal (A), ventral (B) and lateral (C) views of the cartilages; ventral (D) and lateral (E) views of the bony elements. Dotted lines represent unclear limits. Dashes indicate hidden structures. Abbreviations: AN, angular; BH, basihyal; BR.RAY, branchiostegal ray; CBR, ceratobranchial; CBR 5, ceratobranchial of the fifth arch; $\mathrm{CH}$, ceratohyal; DE, dentary; EBR, epibranchial; EPH, epiphyseal bar; ETHM.P, ethmoid plate; EXOC, exoccipital; H.B, hyoid bar;HBR 2, hypobranchial of the second arch; HH, hypohyal; HSY, hyosymplectic; IO, interopercle; MAX, maxilla; M.CA, Meckel's cartilage; NC, notochord; ON, lamina orbito-nasalis; OP, opercle; OT.CAP, otic capsule; PAL.Q, palato-quadrate; PASPH, parasphenoid; PBR, pharyngobranchial; PC, parachordal plate; PMAX, premaxilla; PO, preopercle; PR.PT, processus pterygoideus; $Q$, quadrate; RAR, retroarticular; SP, suspensorium; T, tooth; TR.FA.F, foramen of trigemino-facialis chamber.

There are entopterygoid and endochondral ossifications in the hyomandibula. The subopercular appears as a narrow bony bar behind the opercle. The upper jaws look more and more like those in the adult (Vandewalle, 1977) by including an ascending process on the premaxillae. The hyoid bars gain a second pair of hypophyals, one basihyal, and an urohyal. The first four pairs of ceratobranchials begin to ossify while the fifth pair is considerably reinforced.

The palatoquadrate produces an articular head to the Meckel's cartilage.

\section{6-DAY-OLD FRY (14.1 MM) (FIG. 8)}

The stage is characterized by the separation of the ethmoid plate from the parachordals. Despite medio-dorsal growth, the lateral walls do not fuse in the midline as yet. The spheno-ethmoid commissure is almost achieved by confluence of the taenia marginalis and lamina orbito-nasalis.

The vomer appears anteriorly to the parasphenoid, which now completely closes the hypophyseal fenestra.

The anterior pointed notochordal ossification is clearly a part of the future basioccipital; it fits into the bifurcated posterior end of the parasphenoid. The 

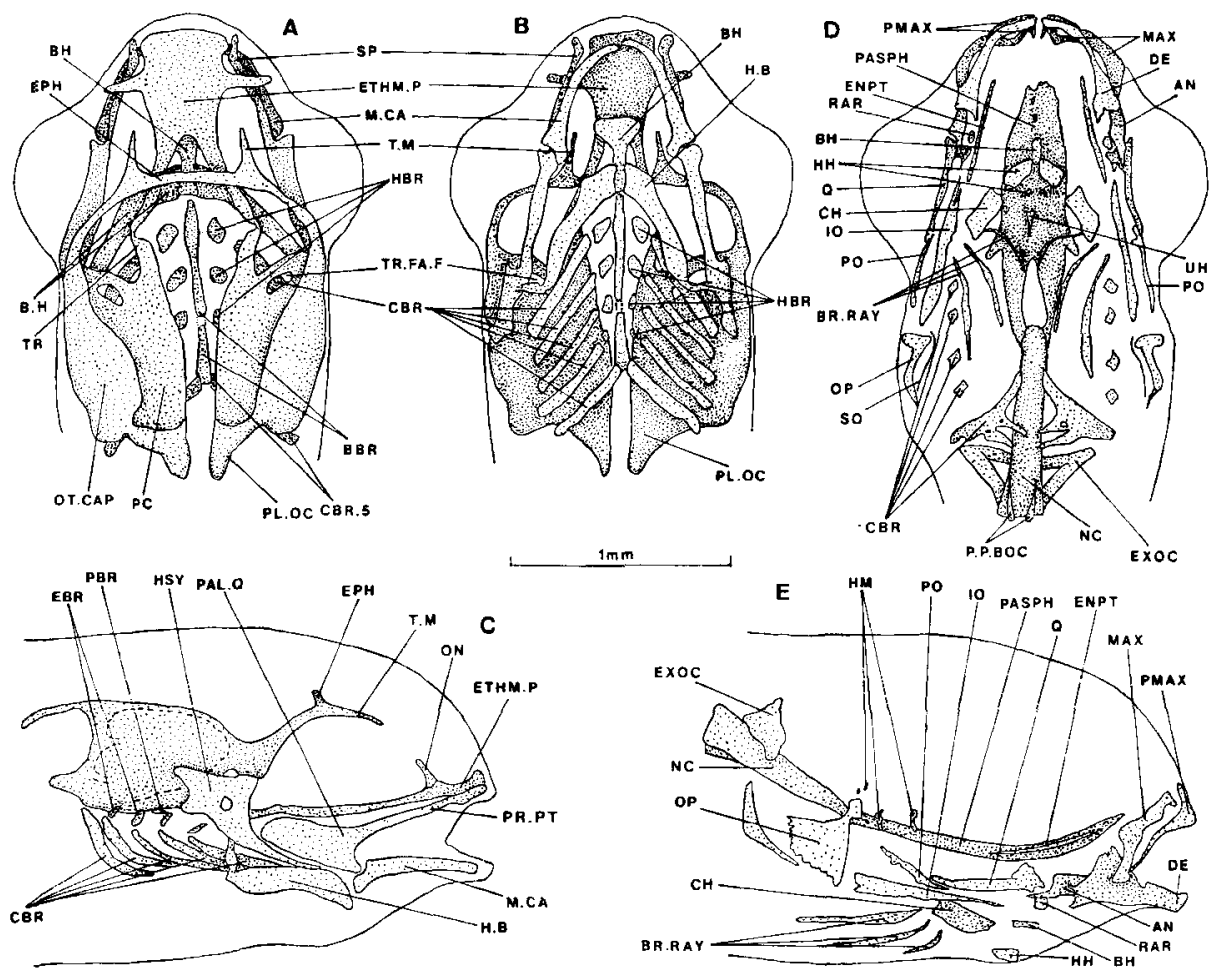

FIG. 7. Barbus barbus, skull of 14-day-old fry. Dorsal (A), ventral (B) and lateral (C) views of the cartilages; ventral (D) and lateral (E) views of the bony elements. Dotted lines represent unclear limits. Dashes indicate hidden structures. Abbreviations: AN, angular; BBR, basibranchial; BH, basihyal; BR.RAY, branchiostegal ray; CBR, ceratobranchial; CBR 5, ceratobranchial of the fifth arch; $\mathrm{CH}$, ceratohyal; DE, dentary; EBR, epibranchial; ENPT, entopterygoid; EPH, epiphyseal bar; ETHM.P, ethmoid plate; EXOC, exoccipital; H.B, hyoid bar; HBR, hypobranchial; HH, hypohyal; HM, hyomandibula; HSY, hyosymplectic; IO, interopercle; MAX, maxilla; M.CA, Meckel's cartilage; NC, notochord; ON, lamina orbito-nasalis; OP, opercle; OT.CAP, otic capsule; PAL.Q, palatoquadrate; PASPH, parasphenoid; PBR, pharyngobranchial; PC, parachordal plate; PL.OC, pila occipitalis; PMAX, premaxilla; PO, preopercle; P.P.BOC, posterior process of the basioccipital; PR.PT, processus pterygoideus; Q, quadrate; RAR, retroarticular; T.M, taenia marginalis; TR, trabecular bar; TR.FA.F, foramen of trigemino-facialis chamber; UH, urohyal.

posterior process of the basioccipital is well developed. The exoccipitals are considerably enlarged.

A slightly ossified kinethmoid [so-called rostral by Ramaswami $(1955 a, b)$ for example], a second pharyngobranchial between the first two epibranchials and a special element above the fourth epibanchial, called the posterior epibranchial, appear in the cartilaginous splanchnocranium.

At the same time, the anterior elements of the splanchnocranium show a tendency to divide into several pieces. The pars palatina becomes separated from the rest of the palato-quadrate. The symplectic detaches from the hyomandibula as well as the interhyal.

There is a constriction in the middle region of the hyoid bar, somewhat similar to that in adult cyprinids (Vetter, 1878; Ramaswami, 1955a, $b$; Vandewalle, 1975, 1977). 

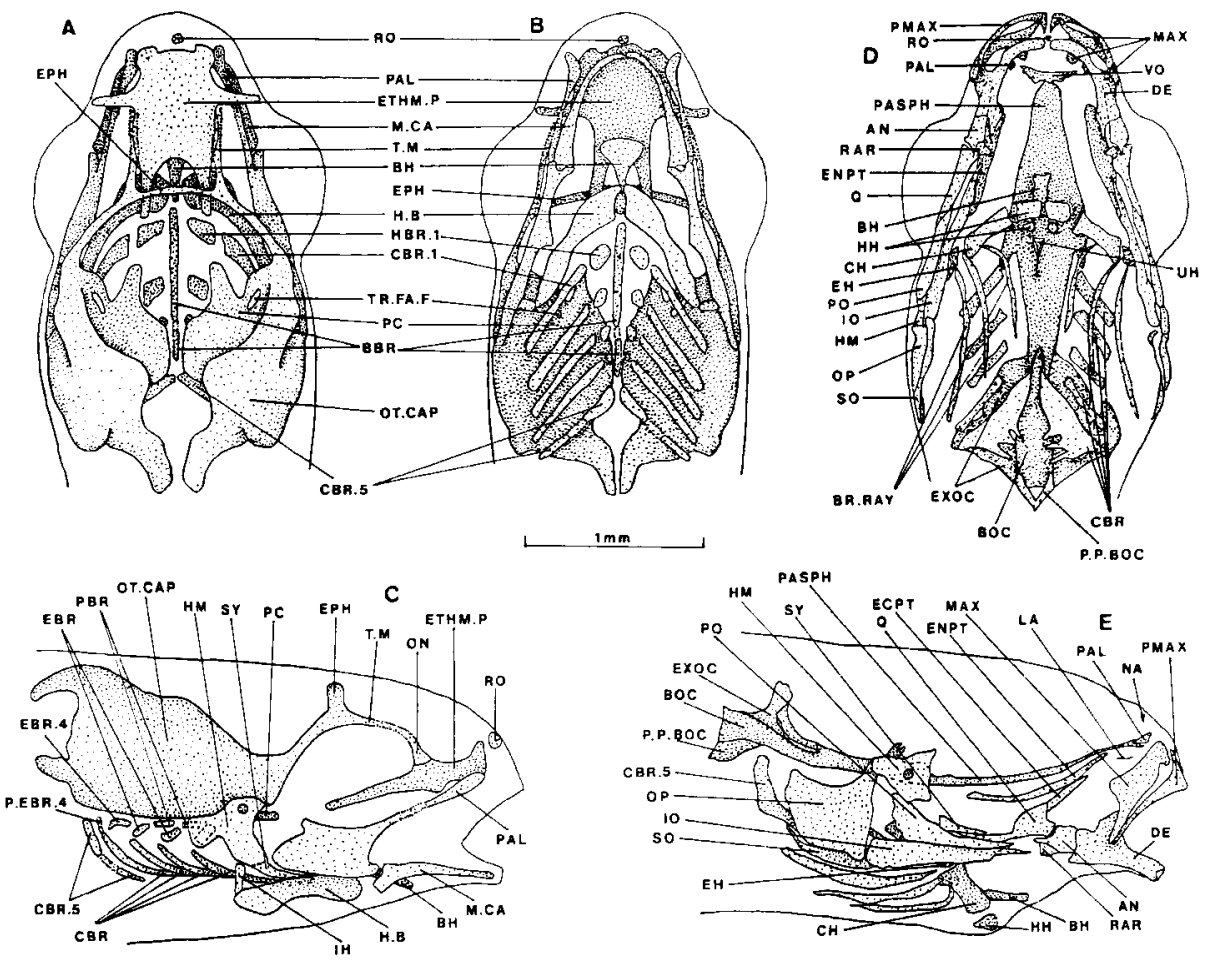

FIG. 8. Barbus barbus, skull of 16-day-old fry. Dorsal (A), ventral (B) and lateral (C) views of the cartilages; ventral $(D)$ and lateral $(E)$ views of the bony elements. Dotted lines represent unclear limits. Dashes indicate hidden structures. Abbreviations: AN, angular; BBR, basibranchial; BH, basihyal; BOC, basioccipital; BR.RAY, branchiostegal ray; CBR, ceratobranchial; CBR 5, ceratobranchial of the ffth arch; CH, ceratohyal; DE, dentary; EBR, epibranchial; ECPT, ectopterygoid; EH, epihyal; ENPT, entopterygoid; EPH, epiphyseal bar; ETHM.P, ethmoid plate; EXOC, exoccipital; H.B, hyoid bar; HBR 1, hypobranchial of the first arch; HH, hypohyal; HM, hyomandibula; IH, interhyal; IO, interopercle; LA, lachrymal; MAX, maxilla; M.CA, Meckel's cartilage; NA, nasal; ON, lamina orbito-nasalis; OP, opercle; OT.CAP, otic capsule; PAL, palatine; PASPH, parasphenoid; PBR, pharyngobranchial; PC, parachordal plate; P.EBR.4, posterior fourth epibranchial; PMAX, premaxilla; PO, preopercle; P.P.BOC, posterior process of the basioccipital; Q, quadrate; RAR, retroarticular; RO, kinethmoid (so-called rostral); SO, subopercle; SY, symplectic; T.M, taenia marginalis; TR.FA.F, foramen of trigemino-facialis chamber; UH, urohyal; VO, vomer.

The bony splanchnocranium is almost complete. A palatine ossification and an extopterygoid are present. A posterior process of the hyomandibula seems to articulate with the opercle, but it is not sure that the joint is already functional. The lower jaw and the quadrate are in a similar situation. The opercular bones and the preopercle are much enlarged. The maxillae closely resemble those in the adults (Vetter, 1878; Ramaswami, 1975a, $b$; Vandewalle, 1975, 1977). The urohyal is now shaped like that of the adult.

The first four ceratobranchial ossifications are much longer and the fifth bears three teeth.

\section{0-DAY-OLD FRY (14.8 MM) (FIG. 9)}

The lamina precerebralis appears above the ethmoid plate. The cartilaginous basibranchial is a single piece. The symplectic is completely free from the hyomandibula as is the interhyal from the hyoid bar. 

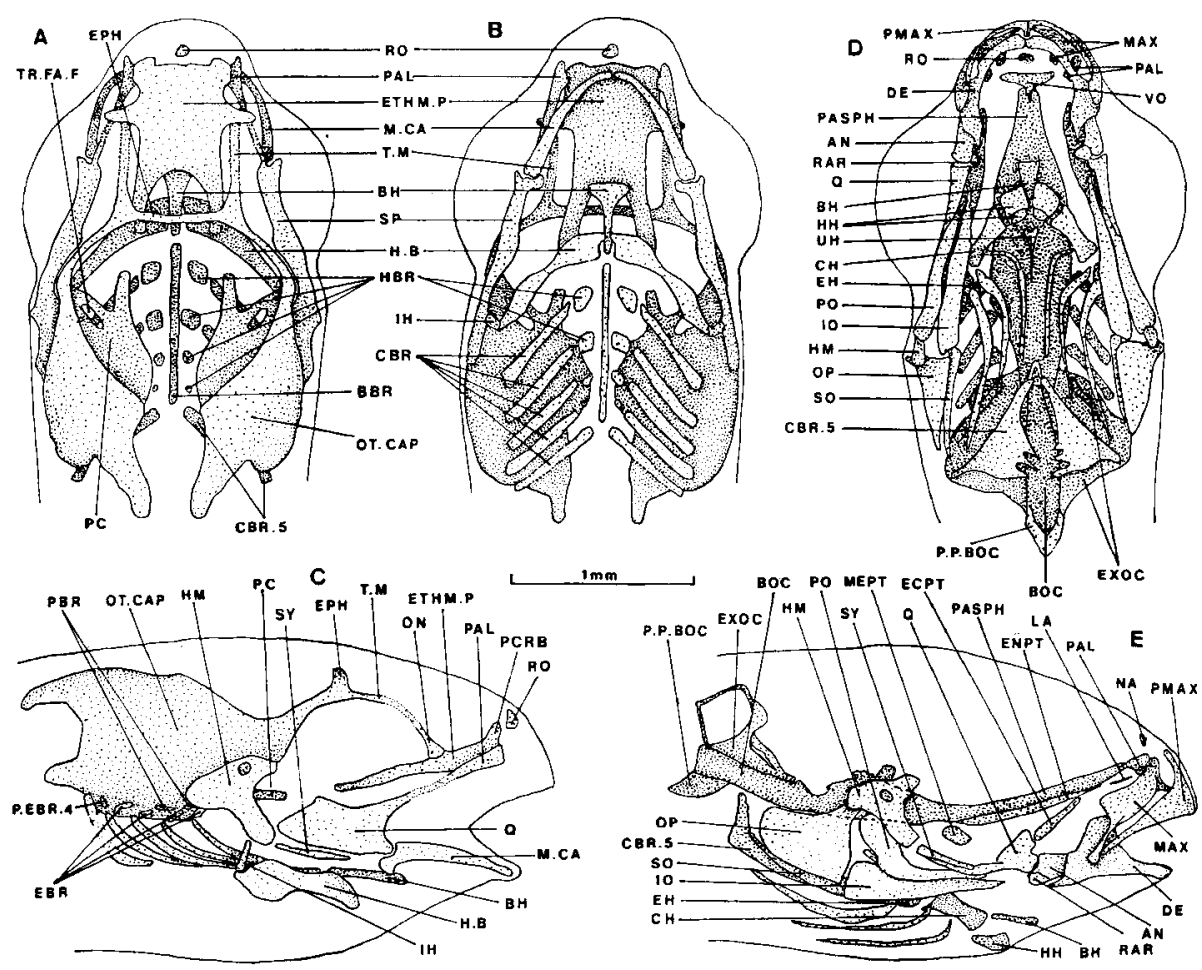

Fig. 9. Barbus barbus, skull of 20-day-old fry. Dorsal (A), ventral (B) and lateral (C) views of the cartilages; ventral (D) and lateral (E) views of the bony elements. Dotted lines represent unclear limits. Dashes indicate hidden structures. Abbreviations: AN, angular; BBR, basibranchial; BH, basihyal; BOC, basioccipital; CBR, ceratobranchial; CBR 5, ceratobranchial of the fifth arch; CH, ceratohyal; DE, dentary; EBR, epibranchial; ECPT, ectopterygoid; EH, epihyal; ENPT, entopterygoid; EPH, epiphyseal bar; ETHM.P, ethmoid plate; EXOC, exoccipital; H.B, hyoid bar; HBR, hypobranchial; HH, hypohyal; HM, hyomandibula; IH, interhyal; IO, interopercle; LA, lachrymal; MAX, maxilla; M.CA, Meckel's cartilage; MEPT, metapterygoid; NA, nasal; ON, lamina orbito-nasalis; OP, opercle; OT.CAP, otic capsule; PAL, palatine; PASPH, parasphenoid; PBR, pharyngobranchial; PC, parachordal plate; PCRB, lamina precerebralis; P.EBR 4, posterior fourth epibranchial; PMAX, premaxilla; PO, preopercle; P.P.BOC, posterior process of the basioccipital; Q, quadrate; RAR, retroarticular; RO, kinethmoid (so-called rostral); $S O$, subopercle; $S P$, suspensorium; SY, symplectic; T.M, taenia marginalis; UH, urohyal; VO, vomer.

The exoccipital ossification encompasses a window which remains present in the adult (Vetter, 1878; Ramaswami, 1955a, $b$; Vandewalle, 1975, 1977). The parasphenoid is still widened at the level of the hyomandibula.

As a consequence of the appearance of the metapterygoid ossification, all the bones of the adult suspensorium are now present.

New canal bones are present: a pair of lachrymals and nasals.

\section{4-DAY-OLD FRY (15.6 MM) (FIG. 10)}

The endocranium is deeply modified: in its anterior part, the taenia marginalis is fused with the lamina orbito-nasalis and with the lamina precerebralis through the new sphenoseptal commissure. The palatine contacts the ethmoid plate. There is a posterior process rising from the epiphyseal bar. The left and right walls of the cartilaginous neurocranium are connected dorsally by the tectum posterius and ventrally by the basal plate. 


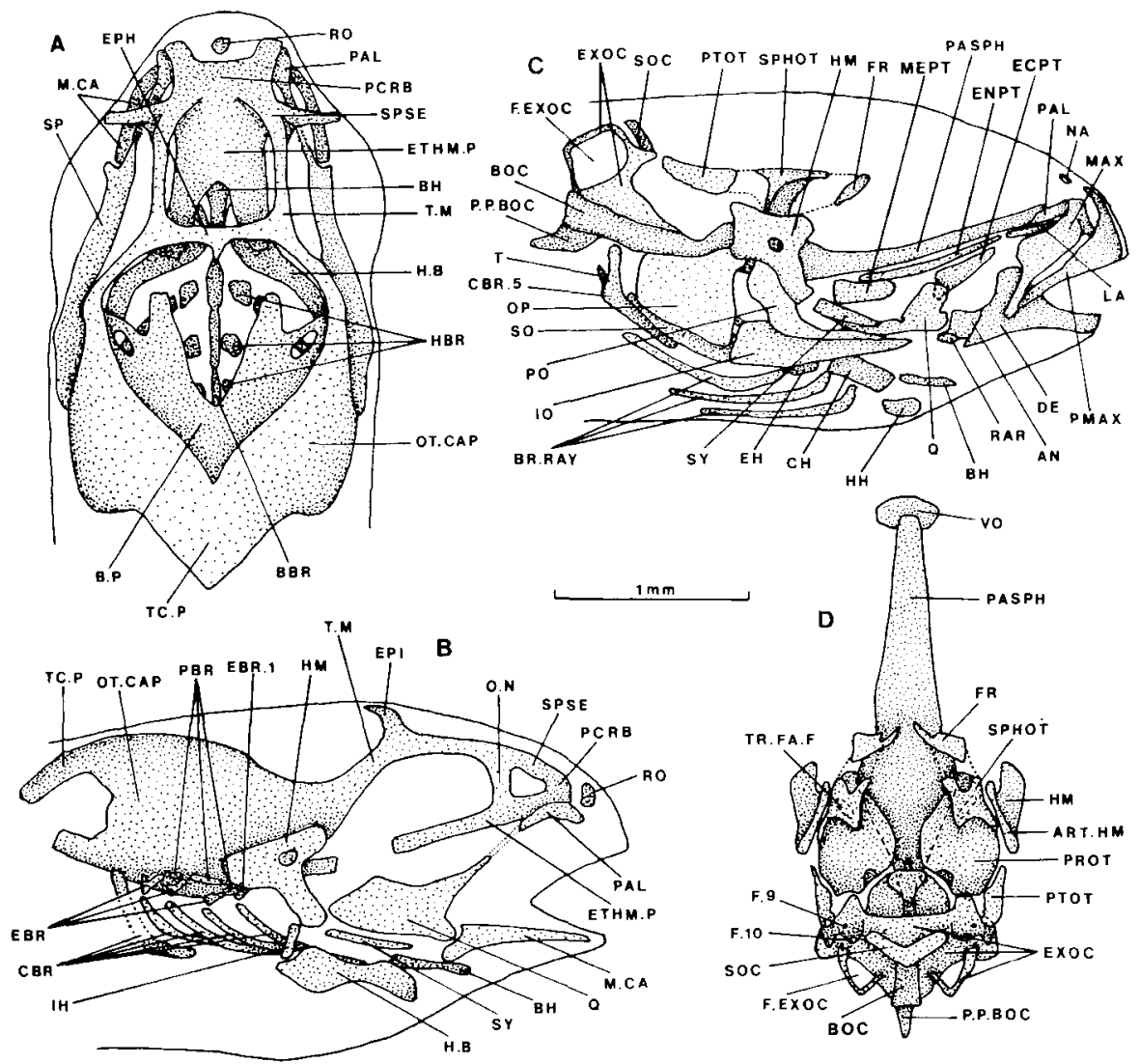

FIG. 10. Barbus barbus, skull of 24-day-old fry. Dorsal (A) and lateral (B) views of the cartilages; lateral view (C) of the bony elements, and dorsal view (D) of the bony neurocranium and hyomandibula. Abbreviations: AN, angular; ART.HM, articular head of the hyomandibula on the neurocranium; BBR, basibranchial; BH, basihyal; BOC, basioccipital; B.P, basal plate; BR.RAY, branchiostegal ray; $\mathrm{CBR}$, ceratobranchial; $\mathrm{CH}$, ceratohyal; DE, dentary; EBR, epibranchial; ECPT, ectopterygoid; EH, epihyal; ENPT, entopterygoid; EPH, epiphyseal bar; ETHM.P, ethmoid plate; EXOC, exoccipital; F.EXOC, fenestra exoccipitalis; FR, frontal; F9, foramen for glossopharyngeal nerve; F. I0, foramen for vagus nerve; H.B, hyoid bar; HBR, hypobranchial; HH, hypohyal; HM, hyomandibula; IH, interhyal; IO, interopercle; LA, lachrymal; MAX, maxilla; M.CA, Meckel's cartilage; MEPT, metapterygoid; NA, nasal; ON, lamina orbito-nasalis; OP, opercle; OT.CAP, otic capsule; PAL, palatine; PASPH, parasphenoid; PBR, pharyngobranchial; PCRB, lamina precerebralis; PMAX, premaxilla; PO, preopercle; P.P.BOC, posterior process of the basioccipital; PROT, prootic; PTOT, pterotic; Q, quadrate; RAR, retroarticular; RO, kinethmoid (so-called rostral); SO, subopercle; SOC, supraoccipital; SPHOT, sphenotic; SPSE, commissura sphenoseptalis; SY, symplectic; T, tooth; TC.P, tectum posterius; T.M, taenia marginalis; TR.FA.F, foramen of trigemino-facialis chamber; VO, vomer.

New bones are present in the posterior neurocranium: the pterotics, sphenotics and frontals have appeared as well as the prootics which are not yet joined by a median bridge; the exoccipitals join in the mid-line under the nerve cord. Foramina of the glossopharyngeal and vagus nerves are conspicuous in the exoccipital as is the posterior aperture of the trigemino-facialis chamber in the prootics. The dorsal bony vault is beginning to form from the sphenotics, the frontals and the supraoccipital. 
The only ossifications in the ethmoid part of the skull are the vomer and the parasphenoid.

In the splanchnocranium, the cartilaginous primordia of the third pharyngobranchials have developed, and those of the posterior fourth epibranchials appear as appendages of the fourth epibranchials. The ossifications of the visceral arches are enlarged, especially the hyomandibula, the articular part of which is widened and provided with two articular condyles. New ossifications appear in the branchial arches, in the epibranchials and in the ventral end of the third hypobranchials, where ligaments insert. Each of the fifth ceratobranchials possesses seven teeth; these structures have nearly the adult shape (Vetter, 1878; Vandewalle, 1977).

\section{DISCUSSION}

Comparison of skull development in teleosts is difficult because of important differences in morphological state at hatching, differences in the timing of development related to specific and individual pecularities, and to condition of laboratory maintenance. Moreover, authors disagree with the significance and definition of stages and few studies cover series that include all of the stages from hatching to the adult state.

\section{CRANIAL CARTILAGES}

Three days before hatching, there is no trace of cartilage in the chrondrocranium of B. barbus; but in Salmo trutta L., parachordals are present 6 days before hatching and 1 day later the trabeculae are fused with the parachordals (De Beer, 1937).

At hatching, the neurocranium of $B$. barbus consists of four elements, two trabeculae and two parachordals, just as in the catfish Heteropneustes fossilis (Bloch) (stage $3.5 \mathrm{~mm}$, hatching) (Srinivasachar, 1959). Fusion does not occur before 7 days in $B$. barbus but it is sooner in $H$. fossilis.

In the cyprinid Rutilus rutilus L., only trabeculae are formed in the first stage (Hubendick, 1942) but they soon fuse together and with the parachordals. In the catostomid Catostomus commersoni Lacépède, the hatchling is devoid of any cranial cartilage, but the trabeculae arise soon and also fuse together and with the parachordals (Elman \& Balon, 1980). The situation at hatching is similar in Mastacembelus armatus (Curr \& Val.) (Bhargava, 1958) and in Clarias gariepinus (Burchell) (Surlemont \& Vandewalle, 1991). In the latter species, early development is extremely fast, such that only a few hours later, there is a very complete neurocranial floor to which the splanchnocranial elements fused in one piece are united.

After hatching, the order of appearance and the course of development of the cranial elements is highly variable in teleosts. For example, the ethmoid and orbital regions appear before the otic capsules in Anguilla anguilla L. while in Merlangius merlangus L. the hind part of the neurocranium develops faster (De Beer, 1937); in H.fossilis, the basal plate is completed early, and soon after, the fore part develops (Srinivasachar, 1958) as it does in C. gariepinus (Surlemont et al., 1989; Surlemont \& Vandewalle, 1991).

In $B$. barbus, the anterior and posterior parts of the neurocranium develop simultaneously but slowly: the taenia marginalis and the lamina orbito-nasalis, as well as the ventral and dorsal parts of the braincase, meet and fuse only at 24 days 
while this is already realized in a $10-\mathrm{mm}$ Ictalurus nebulosus Le Seneur fry (Kindred, 1919).

The ethmoid plate of $B$. barbus appears as a single piece and not as two separate trabeculae as it does in other cyprinids such as $R$. rutilus (Hubendick, 1942) and C. commersoni (Elman \& Balon, 1980). It is notable that the trabecular region separates at 16 days from the parachordal plates, seemingly at the very level at which they had fused at 6 days; that event occurs with respect to the general level of cranial development sooner than in most other species (Kindred, 1919; De Beer, 1937).

The braincase of B. barbus fry is not widely fenestrated as in $S$. trutta (De Beer, 1937). The only foramen of the trigemino-facialis chamber is most probably the posterior one because, the anterior one opens behind the eye socket in adult cyprinids (Vandewalle, 1974); it would be the fenestra basicapsularis anterior; there would be no pila lateralis nor commissura lateralis in B. barbus. The other fenestrae were not found (because of the limits of the method of observation) so that it is impossible to decide if the posterior truss of the braincase is the pila occipitalis (as it is commonly called in the literature) or the commissura basicapsularis posterior; in the first case, the posterior part of the skull roof is a tectum posterius, in the second one, it is a tectum synoticum.

The neurocranium does not grow at the same rate throughout its development; it grows regularly for 14 days. From the 14 th or the 16 th day up to the 20 th day, growth almost stops. After that pause, development proceeds markedly to reach the level of the 24-day fry.

A part of the splanchnocranium is present at hatching in B. barbus, although it is lacking at that time in other cyprinids (Hubendick, 1942; Elman \& Balon, 1980) in which it appears a short time later. In S. trutta (De Beer, 1937), the splanchnocranium is already as developed as in $B$. barbus at 10 days. In $M$. merlangus, splanchnocranial primordia exist before neurocranial ones.

When comparing the development of the splanchnocranium in teleosts, the most noticeable fact is that in many species, the splanchnocranium consists of at least one stage as a single cartilaginous primordium while in other species it develops, during all the larval stages, from several discrete pieces, at least a hyosymplecticum and a palatoquadrate including a processus pterygoideus (Kadam, 1961; Elman \& Balon, 1980). In 'intermediate' cases, the palato-quadrate and the Meckelian cartilage (Hubendick, 1942) or the palatoquadrate and the hyosymplectic (Kindred, 1919) may fuse for a definite period.

The splanchnocranium of $\boldsymbol{B}$. barbus grows regularly and four major elements are soon conspicuous: the palato-quadrate, the hyosymplectic, the Meckelian cartilage and the hyoid bar. Very early, the hyosymplectic and the Meckelian cartilage reach a stable shape while the processus pterygoideus progressively develops from the palato-quadrate; its anterior end later separates from the palatoquadrate and gives rise to the autopalatine; the autopalatine is free at the first onset only to be found in catfishes (Kindred, 1919; Srinivasachar, 1959; Surlemont et al., 1989; Surlemont \& Vandewalle, 1991). In the splanchnocranium of B. barbus, only the hyosymplectic, the interhyal and the hyoid bar fuse for a time, at first the hyoid bar with the interhyal, and then the interhyal with the hyosymplectic.

The first four ceratobranchials appear at the same time; the fifth one, which develops later, is at its first appearance dumpy and curved somewhat as in adult 
cyprinids (Vetter, 1878; Ramaswami, 1955a, b; Vandewalle, 1975). In R. rutilus and $C$. commersonii, the five ceratobranchials appear together (Hubendick, 1942; Elman \& Balon, 1980); but in H. fossilis (Srinivasachar, 1959) and C. gariepinus (Surlemont et al., 1989; Surlemont \& Vandewalle, 1991) they appear progressively from anterior to posterior, and in Gasterosteus aculeatus L. and S. trutta (De Beer, 1937), they develop as in B. barbus.

In $B$. barbus, the remaining branchial elements appear progressively: the epibranchials and thereafter the pharyngobranchials, while in some other teleosts the anterior epibranchials arise before the posterior ceratobranchials (Srinivasachar, 1959). The fourth epibranchial of $B$. barbus results from the fusion of two epibranchial primordia, the posterior one becoming a sort of spur on the anterior one; as Holstvoogt (1965) described five epibranchials in the cyprinid Leuciscus cephalus $\mathrm{L}$., such a fusion is perhaps not a general rule.

At 16 days a very striking feature takes place in chondrocranial development which deserves attention. Simultaneously, the palatine, the symplectic, the hyomandibula and the hyoid bar gain individuality and the fifth epibranchial divides into two parts while the neurocranium remains and will remain for a time, in a very incomplete state. It seems that there are two different rates of development, that for the bucco-pharyngeal apparatus being faster than that for the neurocranium.

\section{CRANIAL BONES AND OSSIFICATION}

Despite wide variation in the patterns of development of bones in the skull among teleosts (De Beer, 1937; Bamford, 1948; Jollie, 1984; Matsuura \& Yoneda, 1987), the first bones to appear are always dermal bones of the splanchnocranium. In B. barbus, many bones appear together in 8-day-old fry: the opercle, the dentary, a thin maxilla, a branchiostegal ray and minute angular and retroarticular ossifications. In Onchorynchus mykiss Walbaum (Verraes, 1977) and C. gariepinus (Surlemont et al., 1989) the first element is an opercular bone, in Galeichthys felis Val., a small dentosplenial (Bamford, 1948) and in $R$. rutilus, the fifth ceratobranchial (Hubendick, 1942). In Lophius gastrophysis Ribeiro, the first bones observed simultaneously are a premaxilla, a maxilla, a dentary, an articular and a preopercle (Matsuura \& Yenoda, 1987); in Nerophis aequoreus Day, they are a premaxilla, a maxilla, a dentary and an angular (Kadam, 1961).

In O.mykiss and in N.aequoreus (Kadam, 1961; Verraes, 1974), the parasphenoid appears at the same time as the splanchnocranial bones. It is the first neurocranial ossification of teleosts, sometimes together with the prevomer (if the notochordal ossification is not taken into account) (Kadam, 1961; Dornesco \& Soresco, 1971; Verraes, 1974; Ismail et al., 1982; Surlemont \& Vandewalle, 1991).

As mentioned by De Beer (1937), bones develop in the visceral arches sooner than in the neurocranium of the teleosts. All the bony ossifications of the splanchnocranium of $B$. barbus are present at 20 days, while at the same time there are still only four bones in the neurocranium. At 16 days the buccal and pharyngeal skeletal elements are almost adult-like (Ballintijn, 1969; Vandewalle, 1979), so that the mouth seems already to be protrusile. A similar situation exists in $\mathrm{Cl}$. gariepinus (Surlemont \& Vandewalle, 1991), Haplochromis elegans Trewavas (Otten, 1982; Ismail et al., 1982) and Amphistichus argenteus Agassiz (Morris \& Gaudin, 1982). 
The first endochondral ossification of the suspensorium is in the quadrate which soon gives rise to an articular head for the mandible, as in $N$. aequoreus (Kadam, 1961). Even though the hyomandibula ossifies later than the quadrate, it seems that its articulation with the braincase becomes functional in the same time period as the quadratomandibular joint; the same seems to be true for the hyomandibuloopercular joint. So three major articular regions of the suspensorium are well developed while its other parts are still separate ossifications. Jollie (1975) observed a similar case in Esox lucius L.

Neurocranial ossification progresses relatively slowly in $B$. barbus. From the time of appearance of the parasphenoid to 20 days, only the vomer, the exoccipital and the processus posterior of the basioccipital become ossified; they do not constitute a complete bony floor and there is no trace of a bony roof. In $H$. elegans, the frontal appears over the taenia marginalis soon after the appearance of the parasphenoid (Verraes \& Ismail, 1980; Ismail et al., 1982). In N. aequoreus, Kadam (1961) observed a frontal and a supraoccipital forming after the parasphenoid and the vomer, but at the same time as the ethmoid bone.

The bony neurocranium ossifies faster, between 20 and 24 days, but solely in the braincase, while the ethmoid region remains inactive. There is some parallelism between development of the chondrocranium and the osteocranium. In both cases, the splanchnocranium progresses before the neurocranium.

\section{CONCLUSIONS}

Development of the skull is not regular; slow and fast periods alternate and developmental rates are different in different cranial regions (Table I). The path of development is related to survival functional needs of the fry. At hatching, in $B$. barbus as in many other teleostean species, respiration takes place through the skin and the well vascularized yolk sac plays an important role. As the yolk-sac volume decreases, the branchial system must take over respiration, and the first four branchial arches shortly appear. The fifth arch, devoid of a respiratory role appears later; it plays a part in the exogenous feeding process and must be functional 14 days after hatching when the vitelline vesicle is exhausted. The buccal cavity must be functional also and well shaped enough to insure efficient food trapping. As in Cl.gariepinus (Surlemont \& Vandewalle, 1991) the parasphenoid, the first bone to ossify in the braincase, appears at the same time; it seems to reinforce the cranial floor and to prevent unwanted communication between the brain and the mouth cavity. Moreover ' cheeks' are completed by dermal bones, and jaw bones develop in such a way that greater efficiency is gained in prey catching, involving aspiration as in many other teleosts (Van Leeuwen \& Muller, 1984; Lauder, 1985). A conical prebuccal cavity forms in front of the mouth cavity (Vandewalle, 1978, 1980) and improves the efficiency of the aspiration of food (Muller \& Osse, 1983). This cavity results from the protrusion of the upper jaw in which the kinethmoid plays a prominent function (Ballintijn, 1969; Vandewalle, 1978). At 14 days, the kinethmoid is still absent and the shape of the buccal skeletal elements is not yet adequate for protrusion, but at 16 days, these elements seem perfectly able to perform it.

In $B$. barbus, food is handled by the pharyngeal jaws constituted by the fifth ceratobranchials (Sibbing, 1982). These bones are the last ceratobranchials to 
TABLE I. Events of the skull development of Barbus barbus

\begin{tabular}{lll}
\hline Age Cartilage Bones & Be
\end{tabular}

\begin{tabular}{|c|c|}
\hline $\begin{array}{l}\text { Hatching } \\
\text { (4-day-old) } \\
\text { and 5-day-old } \\
\text { (Fig. 1) }\end{array}$ & $\begin{array}{l}\text { Presence: hyoid bar, Meckel's } \\
\text { cartilage, parachordal plate and } \\
\text { trabecular bar }\end{array}$ \\
\hline $\begin{array}{l}\text { 6-day-old } \\
\text { (Fig. 2) }\end{array}$ & $\begin{array}{l}\text { Appearance: commissura } \\
\text { basicapsularis anterior, } \\
\text { ceratobranchials } 1 \text { to } 4 \text {, } \\
\text { hyosymplectic, palato-quadrate, pila } \\
\text { occipitalis }\end{array}$ \\
\hline $\begin{array}{l}\text { 7-day-old } \\
\text { (Fig. 3) }\end{array}$ & $\begin{array}{l}\text { Appearance: } 5 \text { th ceratobranchial, } \\
\text { interhyal, pterygoid process, taenia } \\
\text { marginalis }\end{array}$ \\
\hline $\begin{array}{l}\text { 8-day-old } \\
\text { (Fig. 4) }\end{array}$ & $\begin{array}{l}\text { Appearance: basibranchial, basihyal, } \\
\text { ethmoid plate, hypobranchials, otic } \\
\text { capsule } \\
\text { Fusion: trabecular bar and } \\
\text { parachordal plate, interhyal and } \\
\text { hyoid bar }\end{array}$ \\
\hline $\begin{array}{l}\text { 10-day-old } \\
\text { (Fig. 5) }\end{array}$ & $\begin{array}{l}\text { Appearance: lateral wall of the otic } \\
\text { capsule }\end{array}$ \\
\hline $\begin{array}{l}\text { 12-day-old } \\
\text { (Fig. 6) }\end{array}$ & $\begin{array}{l}\text { Appearance: epibranchials, } \\
\text { epiphyseal bar, lamina orbito- } \\
\text { nasalis, one pharyngobranchial, otic } \\
\text { wall curved inward } \\
\text { Fusion: interhyal, hyoid bar and } \\
\text { hyosymplectic }\end{array}$ \\
\hline
\end{tabular}

14-day-old

(Fig. 7)

16-day-old

(Fig. 8)

Appearance: kinethmoid, posterior epibranchial 4

Fusion: taenia marginalis and lamina orbito-nasalis

Separation: ethmoid plate and parachordal plate, hyomandibula and symplectic, hyomandibula and interhyal

20-day-old (Fig. 9)

Appearance: lamina precerebralis Separation: hyoid bar and interhyal, palatine and quadrate, 5 th ceratobranchial in two parts sphenoseptalis, tectum posterius Fusion: epibranchial 4 and posterior epibranchial 4

Appearance: angular, one branchiostegal ray, dentary, maxilla, opercle, retroarticular

Appearance: other branchiostegal rays, 5 th ceratobranchial, interopercle, parasphenoid, quadrate Appearance: ceratohyal, exoccipital, hypohyal, premaxilla, preopercle, 2 teeth

Appearance: basihyal, ceratobranchials 1 to 4 , entopterygoid, hyomandibula, posterior process of the basioccipital, urohyal

Appearance: basioccipital, ectopterygoid, epihyal, kinethmoid, lachrymal, nasal, palatine, subopercle, symplectic, 3 teeth, vomer, adult shape of maxilla and premaxilla. articulation quadrate-mandible

Appearance: exoccipital fenestra, metapterygoid

Appearance: frontal, prootic, pterotic, sphenotic, supraoccipital 
appear but they ossify earlier than their serial homologues. They meet the mechanical requirements of feeding, which do not involve the other branchial arches, the respiratory function of which is possible with cartilage alone.

The other cephalic structures of the B. barbus fry are not submitted to such vital needs. Their growth and development are slower and delayed to after those structures related to primary survival needs.

We would like to thank Dr Philippart and Dr Mélard (University of Liège) for providing larvae and fry of $B$. barbus. This work was supported by Research grant no. 2.9006.90 from the Belgian Fonds de la Recherche Fondamentale Collective. P.V. and B.F. are Research Associates of the Belgian Fonds National de la Recherche Scientifique.

\section{References}

Able, K. W., Fahal, M. P. \& Markle, D. F. (1986). Development of larval snailfishes (Pisces Cyclopteridae Liparidinae) from the western north Atlantic. Canadian Journal of Zoology 64, 2294-2316.

Arratia, G. \& Schultze, H. P. (1990). The urohyal: development and homology within Osteichthyans. Journal of Morphology 203, 247-282.

Badenhorst, A. (1989a). Development of the chondrocranium of shallow-water Cape lake Merluccius capensis (Cast.). Part 1: Neurocranium. South African Journal of Zoology 24, 33-48.

Badenhorst, A. $(1989 b)$. Development of the chondrocranium of the shallow-water Cape lake Merluccius capensis (Cast.). Part 2: Viscerocranium. South African Journal of Zoology 24, 49-57.

Ballintijn, C. M. (1969). Muscle co-ordination of the respiratory pump of the carp (Cyprinus carpio L.). Journal of Experimental Biology 50, 569-591.

Bamford, T. W. (1948). Cranial development of Galeichthys felis. Proceedings of the Zoological Society, London 118, 364-391.

Benmouna, H., Trabert, I., Chardon, M. \& Vandewalle, P. (1984). Comparaison morphologique du neurocrâne et du splanchnocrâne de Serranus scriba (Linné, 1758) et Serranus cabrilla (Linné, 1758) (Pisces, Serranidae). Cybium 8, 71-93.

Bertmar, G. (1959). On the ontogeny of the chondral skull in Characidae, with a discussion on the chondrocranial base and the visceral chondrocranium in fishes. Acta Zoologica, Stockholm 40, 203-364.

Bhargava, H. N. (1958). The development of the chondrocranium of Mastacembelus armatus (Cuv. et Val.). Journal of Morphology 102, 401-426.

Corsin, J. (1961). Etude de quelques corrélations morphogénétiques dans le développement du chondrocrâne de Salmo. Bulletin de la Société Zoologique de France 86, $772-785$.

Daget, J. (1964). Le crâne des Téléostéens. Mémoires du Muséum National d'Histoire naturelle, Série A, Zoologie 31, 167-340.

De Beer, G. R. (1937). The Development of the Vertebrate Skull. Oxford: Clarendon Press.

Devillers, C. (1944). Morphogenèse de quelques os crâniens chez la truite arc-en-ciel, Salmo irideus (Gibb.). Annales des Sciences Naturelles, Zoologie et Biologie Animale, Série II, 6, 25-31.

Dornesco, G. T. \& Soresco, C. (1971). Développement de quelques os du neurocrâne chez Cyprinus carpio L. Anatomischer Anzeiger 128, 16-38.

Elman, F. Mc. \& Balon, E. K. (1980). Early ontogeny of the white sucker, Catostomus commersoni, with steps of saltatory development. Environmental Biology of Fishes 5, 191-224.

Francillon, H. (1974). Développement de la partie postérieure de la mandibule de Salmo trutta fario L. (Pisces, Teleostei, Salmonidae). Zoologica Scripta 3, 41-51. 
Fukuhara, O. (1988). Morphological and functional development of the larval and juvenile Limanda yokohamae (Pisces: Pleuronectidae) reared in the laboratory. Marine Biology 99, 271-281.

Gaupp, E. (1903). Zur Entwicklung der Schädelknochen bei den Teleostiern. Verhandlungen der anatomischen Gesellschaft, Iena 1903, 113-123.

Gegenbaur, C. (1878). Ueber das Kopfskelet von Alepocephalus rostratus. Morphologische Jarhbücher 4, 1-41.

Haines, R. W. (1937). The posterior end of Meckel's cartilage and related ossifications in bony fishes. Quarterly Journal of Microscopical Sciences 80, 1-38.

Holstvoogd, C. (1965). The pharyngeal bones and muscles in Teleostei, a taxonomic study. Proceedings of the Koninglijk Nederlandse Akademie van Wetenschappen, serie C 68, 209-218.

Howes, G. J. \& Sanford, C. P. J. (1987). Oral ontogeny of the ayu, Plecoglossus altivelis and comparisons with jaws of other salmoniform fishes. Zoological Journal of the Linnean Society 89, 133-169.

Hubendick, B. (1942). Zur Kenntnis der Entwicklung des Primordialcraniums bei Leuciscus rutilus. Arkiv für Zoologi 34, 1-35.

Ismail, M.H., Verraes, W.\& Huysseune, A. (1982). Developmental aspect of the pharyngeal jaws in Astatotilapia elegans (Trewawas, 1933) (Teleostei: Cichlidae). Netherlands Journal of Zoology 32, 513-543.

Jollie, M. (1975). Development of the head skeleton and pectoral girdle in Esox. Journal of Morphology 147, 61-88.

Jollie, M. (1984). Development of the head skeleton and pectoral girdle of salmons, with a note on the scales. Canadian Journal of Zoology 62, 1757-1778.

Kadam, K. M. (1961). The development of the skull in Nerophis (Lophobranchii). Acta Zoologica, Stockholm 42, 1-42.

Kapoor, A. S. (1970). Development of dermal bones related to sensory canals of the head in the fishes Ophiocephalus punctatus Bloch (Ophiocephalidae) and Wallago attu B1. \& Sch. (Siluridae). Journal of the Linnean Society of London, Zoology 49, 69-97.

Kindred, J. E. (1919). Development of the skull in Amiurus. III. Biological Monographs 5, $7-121$.

Krupka, I. (1988). Early development of the barbel [Barbus barbus (Linnaeus, 1758)]. Prace Ústavu rybárstva a Hydrobiologie 6, 115-138.

Lauder, G. V. (1985). Aquatic feeding in lower vertebrates. In Functional Vertebrate Morphology (Hildebrand, M., Bramble, D. M., Liem, K. F. \& Wake, D. B., eds), pp. 210-229. Boston: Harvard University Press.

Lekander, B. (1949). The sensory line system and the canal bones in the head of some Ostariophysi. Acta Zoologica, Stockholm 30, 1-131.

Matsuura, Y.\& Yoneda, N. T. (1987). Osteological development of the lophiid anglerfish, Lophius gastrophysus. Japanese Journal of Ichthyology 33, 360-367.

Morris, S. L. \& Gaudin, A. J. (1982). Osteocranial development in the viviparous surfperch Amphistichus argenteus (Pisces: Embiotocidae). Journal of Morphology 174, 95-120.

Muller, M. \& Osse, J. W. M. (1982). Hydrodynamics of suction feeding in fish. Transactions of the Zoological Society of London 32, 51-135.

Munehara, H. \& Mishima, S. (1986). Embryonic development, larval and juvenile of elkhorn sculpin, Alcichthys alcicornis. Japanese Journal of Ichthyology 33, 46-50.

Nishikawa, Y. (1987). Larval morphology and occurrence of the louvar, Luvarus imperialis (Luvaridae). Japanese Journal of Ichthyology 34, 215-221.

Otten, E. (1982). The development of a mouth-opening mechanism in a generalized Haplochromis species: H. elegans Trewawas 1933 (Pisces, Cichlidae). Netherlands Journal of Zoology 32, 31-48.

Parker, W. K. (1873). On the structure and development of the skull in salmon (Salmo salar). Philosophical Transactions of the Royal Society of London 163, 95-145.

Pottoff, T., Kelly, S. \& Collins, L. A. (1988). Osteological development of the red snapper, Lutjanus campechanus (Lutjanidae). Bulletin of Marine Sciences 43, 1-40. 
Ramaswami, L. S. (1955a). Skeleton of cyprinoid fishes in relation to phylogenetic studies. 6. The skull and Weberian apparatus in the subfamily Gobioninae (Cyprinidae). Acta Zoologica, Stockholm 36, 127-158.

Ramaswami, L. S. (1955b). Skeleton of cyprinoid fishes in relation to phylogenetic studies. 7. The skull and Weberian apparatus in the subfamily Cyprininae (Cyprinidae). Acta Zoologica, Stockholm 36, 199-242.

Sagemehl, M. (1885). Beiträge zur vergleichenden Anatomie der Fische. 3. Das Cranium der Characiniden nebst algemeinen Bemerkungen über die mit einem Weberschen Apparat verschenen Phytostomenfamilien. Morphologische Jahrbücher 10, 1-119.

Sibbing, F. A. (1982). Pharyngeal mastication and food transport in the carp Cyprinus carpio (L.): a cineradiographic and electromyographic study. Journal of Morphology 172, 223-258.

Srinivasachar, H. R. (1958). Development of the skull in catfishes. Part V. Development of skull in Heteropneustes fossilis (Bloch). Proceedings of the National Institute of Sciences, India B 24, 165-190.

Srinivasachar, H. R. (1960). Development of the skull in catfishes. Part III. The development of the chondrocranium in Heteropneustes fossilis (Bloch) (Heteropneustidae) and Clarias batrachus (Linn.) (Clariidae). Morphologische Jahrbücher 101, 373-405.

Stöhr, P. (1882). Zur Entwicklungsgeschichte des Kopfskelettes der Teleostier. In: Festschrift 3 Säkulafeier Alma Julia Maximiliana Universitäts Würzburg, Leipzig 2, $1-23$.

Surlemont, C., Chardon, M. \& Vandewalle, P. (1989). Skeleton, muscles and movements of the head of a $5 \cdot 2-\mathrm{mm}$ fry of Clarias gariepinus (Burchell) (Pisces Siluriformes). Fortschritte der Zoologie 35, 459-562.

Surlemont, C. \& Vandewalle, P. (1991). Développement postembryonnaire du squelette et de la musculature de la tête de Clarias gariepinus (Pisces, Siluriformes) depuis l'éclosion jusqu'à 6.8 mm. Canadian Journal of Zoology 69, 1094-I 103.

Swinnerton, H. H. (1902). A contribution to the morphology of the teleostean head skeleton, based upon a study of the developing skull of the three-spined stickleback (Gasterosteus aculeatus). Quarterly Journal of Microscopical Sciences 45, 503-593.

Taverne, L. (1974). L'ostéologie d'Elops Linné, C. 1766 (Pisces Elopiformes) et son intérêt phylogénétique. Académie Royale de Belgique, Mémoires de la Classe des Sciences 41, 1-96.

Taylor, W. R. \& Van Dyke, G. C. (1985). Revised procedures for staining and cleaning small fishes and other vertebrates for bone and cartilage study. Cybium 9, 107-119.

Tischomiroff, A. (1885). Zür Entwicklung des Schädels bei den Teleostieren. Zoologischer Anzeiger 8, 533-537.

Vandewalle, P. (1974). Contribution à l'étude anatomique et fonctionnelle de la région céphalique de Gobio gobio (L.) (Pisces, Cyprinidae). 2. La chambre trigémino-faciale et quelques structures voisines. Forma et Functio 7, 119-124.

Vandewalle, P. (1975). Contribution à l'étude anatomique et fonctionnelle de Gobio gobio (L.) (Pisces, Cyprinidae). 3. Os, muscles et ligaments. Forma et Functio 8, 331-360.

Vandewalle, P. (1977). Particularités anatomiques de la tête de deux Poissons Cyprinidés, Barbus barbus (L.) et Leuciscus leuciscus (L.). Académie Royale de Belgique, Bulletin de la Classe des Sciences 632, 469-479.

Vandewalle, P. (1978). Analyse des mouvements potentiels de la région céphalique du goujon, Gobio gobio (L.) (Pisces, Cyprinidae). Cybium 6, 15-33.

Vandewalle, P. (1979). Etude cinématographique et électromyographique des mouvements respiratoires chez trois cyprins, Gobio gobio (L.), Barbus barbus (L.) et Leuciscus leuciscus (L.). Cybium 6, 3-28.

Vandewalle, P. (1980). Etude cinématographique et électromyographique de la prise de nourriture et du crachement chez le goujon, Gobio gobio (L.) et la vandoise, Leuciscus leuciscus (L.) (Pisces, Cyprinidae). Cybium 11, 3-14.

Van Leeuwen, J. L. \& Muller, M. (1984). Optimum sucking techniques for predatory fish. Transactions of the Zoological Society of London 37, 137-169. 
Verraes, W. (1974). Some functional aspects of ossifications in the cartilaginous ceratohyal during postembryonic development in Salmo gairdneri Richardson, 1836 (Teleostei: Salmonidae). Forma et Function 8, 27-32.

Verraes, W. (1977). Postembryonic ontogeny and functional anatomy of the ligamentum mandibulo-hyoideum and the ligamentum interoperculo-mandibulare, with notes on the opercular bones and some other cranial elements in Salmo gairdneri Richardson, 1836 (Teleostei: Salmonidae). Journal of Morphology 151, 11-120.

Verraes, W. \& Ismail, M. H. (1980). Developmental and functional aspects of the frontal bones in relation to some other bony and cartilaginous parts of the head roof in Haplochromis elegans Trewawas 1933 (Teleostei, Cichlidae). Netherlands Journal of Zoology 30, 450-472.

Vetter, B. (1878). Untersuchungen zur vergleichenden Anatomie der Kiemen und Kiefermuskulatur des Fisches. Iena Zeitschrift für Naturwissenschaft 12, 431-550.

Wells, F. R. (1923). On the morphology of the chondrocranium of the larval herring (Clupea harengus). Proceedings of the Zoological Society of London 92, 1213-1229.

Winslow, G. M. (1897). The chondrocranium of the Ichthyopsida. Tufts College Studies 5, $147-201$.

Winterbottom, P. (1980). Systematics, osteology and phylogenetic relationship of fishes of the ostariophysan subfamily Anostominae (Characoidei, Anostomidae). Royal Ontario Museum, Life Sciences Contribution 123, 1-112. 